\title{
A!
}

This is an electronic reprint of the original article.

This reprint may differ from the original in pagination and typographic detail.

Climente-Alarcon, Vicente; Sundaria, Ravi; Panchal, Jay; Arkkio, Antero

\section{Simulation of an Induction Motor's Rotor After Connection}

Published in:

IEEE Transactions on Magnetics

DOI:

10.1109/TMAG.2017.2662713

Published: 01/02/2017

Document Version

Peer reviewed version

Please cite the original version:

Climente-Alarcon, V., Sundaria, R., Panchal, J., \& Arkkio, A. (2017). Simulation of an Induction Motor's Rotor After Connection. IEEE Transactions on Magnetics, 53(6), [8202304].

https://doi.org/10.1109/TMAG.2017.2662713

This material is protected by copyright and other intellectual property rights, and duplication or sale of all or part of any of the repository collections is not permitted, except that material may be duplicated by you for your research use or educational purposes in electronic or print form. You must obtain permission for any other use. Electronic or print copies may not be offered, whether for sale or otherwise to anyone who is not an authorised user. 
This is the accepted version of the original article published by IEEE.

(C) 2017 IEEE. Personal use of this material is permitted. Permission from IEEE must be obtained for all other uses, in any current or future media, including reprinting/republishing this material for advertising or promotional purposes, creating new collective works, for resale or redistribution to servers or lists, or reuse of any copyrighted component of this work in other works. 


\title{
Simulation of an Induction Motor's Rotor after Connection
}

\author{
Vicente Climente-Alarcon ${ }^{1}$, Member, IEEE, Ravi Sundaria ${ }^{1}$, Jay Panchal ${ }^{1}$ and Antero Arkkio ${ }^{1}$ \\ ${ }^{1}$ Aalto University, Department of Electrical Engineering and Automation, Espoo, FINLAND
}

\begin{abstract}
Transients have proven to be a specially demanding operation mode for rotor cages in induction motors. The combination of thermal and mechanical stresses causes damage in weak points of the secondary circuit of these machines. A 3D multiphysics computation may shed some light into the conditions under faults such as broken bars develop whilst taking into account phenomena as interbar currents. With the aim of reducing the computational cost involved, this work carries out a 3D simulation of just the rotor during the first 2.5 cycles after a direct-on-line connection, being the tangential component of the magnetic vector potential mapped on its iron surface from the results obtained by 2D locked rotor FE simulation. The results provide an insight into the skin effect and mechanical loads in the cage, a magnetic coupling between the end ring and the shaft as well as the limitations of the weakly coupled magnetoelastic analysis.
\end{abstract}

Index Terms - Induction motors, rotors, electromagnetic transients, magnetomechanical effects, fault diagnosis.

\section{INTRODUCTION}

$\mathrm{T}$ ransients in induction motors have proven especially damaging for the rotor cage [1]. Frequent startups or stall periods of large units cause heavy thermal and mechanical stresses that in addition to structural or manufacturing weak spots develop into breakages of this secondary circuit [2].

Fatigue tests [3] and analytical calculations [4] have been the traditional methods for studying the development of this fault, since the complexity of a Finite Element electromagnetic, thermal and mechanical computation was too big to be carried out. In [3] FEM was used to obtain the speed, and hence the inertial forces during the acceleration of an induction's motor rotor in a startup transient. Separately, the effects of such forces were imposed on a mesh simulating a rotor bar joint to the end ring. Since no thermal effects were considered, the simulation did not correspond to experimental data. Another approach is considered in [4] in which analytical expressions are used to model the skin effect in the rotor bar during stall conditions, as well as its thermal and mechanical (thermal expansion) consequences.

However, if the results are to have impact on design and fault evolution modelling (prognosis) more detailed computations are needed. 3D FE is mandatory if phenomena as interbar currents are taken into account. Thus, this work presents the 3D electromagnetic and mechanical computation of a cage rotor during the first instants after a direct-on-line connection. In order to reduce the computational needs, a value of the magnetic vector potential is imposed on the rotor iron surface, thus not being simulated the stator. Furthermore,

Corresponding author: V. Climente-Alarcon (e-mail: viclial@ieee.org). V. Climente-Alarcon and R. Sundaria contributed equally. weak coupling between the electromagnetic and mechanical solvers is established whilst, due to the short period simulated, temperature rise is not significant according to preliminary studies based on analytical models [5] and therefore no thermal computation is carried out.

\section{APPROACH FOLLOWED}

The formulations used for the electromagnetic and the magnetic forces analysis are presented here.

\section{A. Electromagnetic Analysis}

Several formulations for 3-D electromagnetic modelling are summarized in [6]. In this paper, the AV-A formulation is used for the 3-D simulation with open source FEM software ELMER which is also applied in [7, 8]. The formulation can be derived by means of a magnetic vector potential $\boldsymbol{A}(\boldsymbol{B}=$ $\nabla \times A)$ and an electric scalar potential $V$.

$$
\begin{gathered}
\boldsymbol{E}=-\frac{\partial \boldsymbol{A}}{\partial t}-\nabla V \\
\nabla \times \frac{1}{\mu} \nabla \times \boldsymbol{A}+\sigma \frac{\partial \boldsymbol{A}}{\partial t}+\sigma \nabla V=\mathbf{0} \\
\nabla \cdot\left(\sigma \frac{\partial \boldsymbol{A}}{\partial t}+\sigma V\right)=0
\end{gathered}
$$

Here the magnetic vector potential $\boldsymbol{A}$ has three components $\left(A_{x}, A_{y}, A_{z}\right)$. Equation (2) is derived from the Ampere's law and Faraday law (1), whereas (3) is a representation of the divergence free nature of currents. However, the complete 3-D model of machine has proved to be very computationally expensive as attempted in [9].

In order to avoid performing a complete 3-D machine simulation but keeping the 3-D analysis for rotor calculations, 2-D coupled 3-D formulations have been attempted yielding a considerable computational decrease as illustrated in [10]. Furthermore, the use of 2-D coupled 3-D simulation for electromagnetic and structural dynamics analysis of electrical machine is performed in [11]. Clearly, 2-D coupled 3-D FEM analysis is becoming popular, especially in simulating complex 3-D phenomena. Specifically, using this coupling, 
rotor eddy current losses in induction machine laminations are calculated in [12]. Following that, the method used in this work presents a weak coupling between 2-D and 3-D field simulation i.e. the corresponding 2-D simulation is not affected by computed 3-D solution.

The field distribution within the rotor can be obtained by setting the normal components of the flux and current densities on its boundaries [6]. This normal component of $\boldsymbol{B}$ can be defined by imposing the tangential component of $\boldsymbol{A}$ on those same boundaries, as explained in [12]. Thus, in this work, the coupling between the 2-D field solution and the 3-D mesh is carried out specifying on the iron's surface the tangential component of $\boldsymbol{A}$, which is interpolated from the 2-D vector potential solution. That is, the $A_{z}$ component obtained by a locked rotor 2-D FE simulation for the same time steps is mapped on the surface of the rotor following the skew of the bars. Magnetic and electric insulation is imposed on the external boundaries of air surrounding the end rings' regions. The concepts are illustrated in Fig. 1.

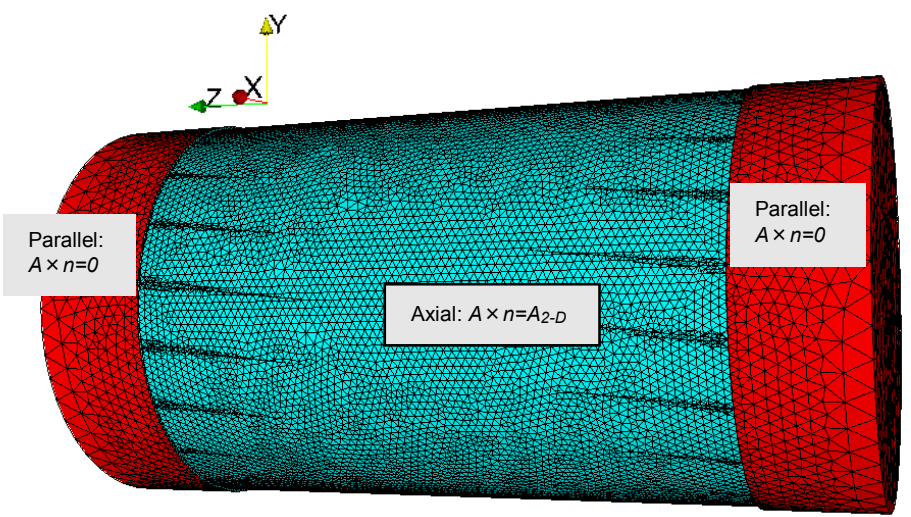

FIG.1. Boundary conditions in the 3-D rotor case when the source of the field is 2-D field solution $\left(\mathrm{A}_{2-\mathrm{D}}\right)$

\section{B. Nodal Forces}

For the mechanical computation, the nodal forces are according to the virtual work principle obtained following the procedure used in [13]. No magnetostriction is taken into account. The magnetic force is calculated differentiating the magnetic energy with respect to a virtual displacement $f_{s}$ that depends on a real parameter $s$ such as $\lim _{s \rightarrow 0} \boldsymbol{f}_{s}(\boldsymbol{x}) \rightarrow \boldsymbol{x}$ :

$$
\begin{gathered}
\frac{\partial \boldsymbol{W}_{s}}{\partial s}=\int \boldsymbol{H}(\boldsymbol{B}) \cdot \frac{\partial}{\partial s} \boldsymbol{J}_{s} \cdot \boldsymbol{B} \\
-\frac{\partial \operatorname{det} \boldsymbol{J}_{s}}{\partial s}\left(\boldsymbol{H}(\boldsymbol{B}) \cdot \boldsymbol{B}-{ }_{0}^{B} \boldsymbol{H} \cdot d \boldsymbol{B}\right) d x
\end{gathered}
$$

where a change of variables and the Piola transformation for the magnetic flux density have been applied. $\boldsymbol{J}_{\boldsymbol{s}}$ is the Jacobian of $\boldsymbol{f}_{\boldsymbol{s}}$. For $\boldsymbol{f}_{\boldsymbol{s}}=\boldsymbol{x}+s \boldsymbol{u} N(\boldsymbol{x})$, where $\boldsymbol{u}$ is the unit vector and $N(\boldsymbol{x})$ a nodal shape function, (4) yields:

$$
\begin{gathered}
\frac{\partial \boldsymbol{W}_{\boldsymbol{s}}}{\partial s}=\int \boldsymbol{H}(\boldsymbol{B}) \cdot \boldsymbol{u} \nabla N \cdot \boldsymbol{B} \\
-\boldsymbol{u} \nabla N\left(\boldsymbol{H}(\boldsymbol{B}) \cdot \boldsymbol{B}-{ }_{0}^{B} \boldsymbol{H} \cdot d \boldsymbol{B}\right) d x
\end{gathered}
$$

These nodal forces are applied in the linear elastic module as body forces and the dynamical equation for elastic deformation of solids solved.

As boundary conditions, the displacement at both ends of the rotor are limited by setting spring boundary conditions on the shaft's cross-sections.

\section{SimULATION}

For comparison purposes two simulations for the first 2.5 cycles of the connection transient in fixed 1e-4 s time steps have been carried out using the rotor featuring closed slots studied in [5], whose dimensions are presented in Table 1. In the first one, one of the bars was narrowed in its connection to the end ring by reproducing the material removed by two drills, creating a hot spot, as shown in Fig. 2. The second one involved a fully symmetrical rotor (the drills were filled, in this case with aluminum instead of air for the simulation). The full mesh comprised 121,738 nodes and the simulations of the transient during $50 \mathrm{~ms}$ took 17 days in a PC.

TABLE 1 Rotor's geometric data

\begin{tabular}{cc}
\hline \hline External radius & $34.75 \mathrm{~mm}$ \\
Iron length & $100 \mathrm{~mm}$ \\
Total length & $140 \mathrm{~mm}$ \\
\hline Number of bars & 20 \\
Radius, top of the bars & $34.5 \mathrm{~mm}$ \\
Radius, bottom of bars & $22 \mathrm{~mm}$ \\
\hline Skew angle & $18^{\circ}$ \\
Area of a bar & $49.25 \mathrm{~mm}^{2}$ \\
Remaining area (hot spot) & $4 \%$ \\
\hline Shaft radius & $14.275 \mathrm{~mm}$ \\
Ring height and initial width & $15 \mathrm{~mm}$ \\
Opening angle (cone) & $10^{\circ}$ \\
Groove depth & $6 \mathrm{~mm}$ \\
\hline \hline
\end{tabular}

The characteristics of the materials (aluminum, silicon steel) utilized in the simulation are summarized in Table 2, where $\sigma$ stands for electrical conductivity, $E$ for the young modulus, $v$ for Poisson ratio, $\mathrm{Al}$ for the aluminum cage and $\mathrm{Fe}$ for all the steel bodies in the rotor, either iron or shaft.

TABLE 2 Material parameters

\begin{tabular}{cc}
\hline \hline$\sigma_{A l}$ & $22 \cdot 10^{8} \mathrm{~S}$ \\
$E_{A l}$ & $70 \cdot 10^{9} \mathrm{~Pa}$ \\
$v_{\mathrm{Al}}$ & 0.35 \\
\hline$\sigma_{\text {iron } x}$ & $4 \cdot 10^{6} \mathrm{~S}$ \\
$\sigma_{\text {iron, } y}$ & $4 \cdot 10^{6} \mathrm{~S}$ \\
$\sigma_{\text {iron } z}$ & 0 \\
\hline$\sigma_{\text {shaft }}$ & $4 \cdot 10^{6} \mathrm{~S}$ \\
$E_{F e}$ & $193.1 \cdot 10^{9} \mathrm{~Pa}$ \\
$v_{\mathrm{Fe}}$ & 0.29 \\
\hline \hline
\end{tabular}




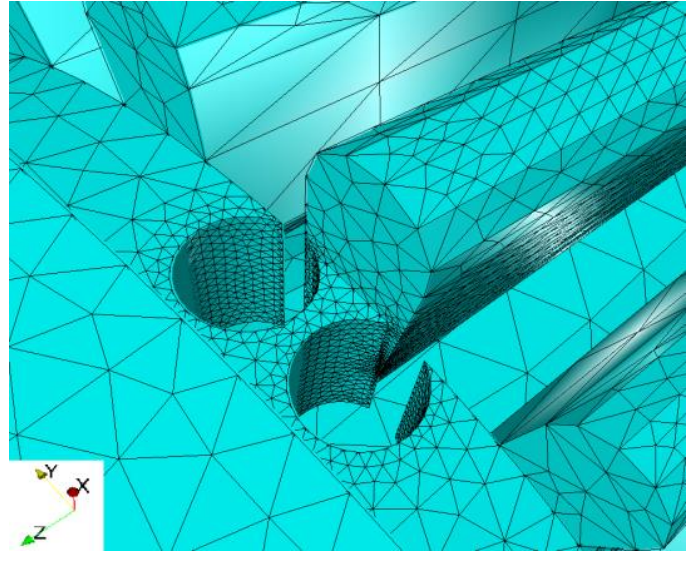

FIG.2. Partial view of the mesh showing the hot spot in the connection of a bar to the end ring. The rotor iron has been removed.

For time constrain reasons, in this study both solvers were weakly coupled; therefore there is no influence of the elastic field on the magnetic field. Fig. 3 shows the tangential component of the magnetic vector potential applied on the rotor iron at two time steps, $25 \mathrm{~ms}$ and $50 \mathrm{~ms}$ (final time step).

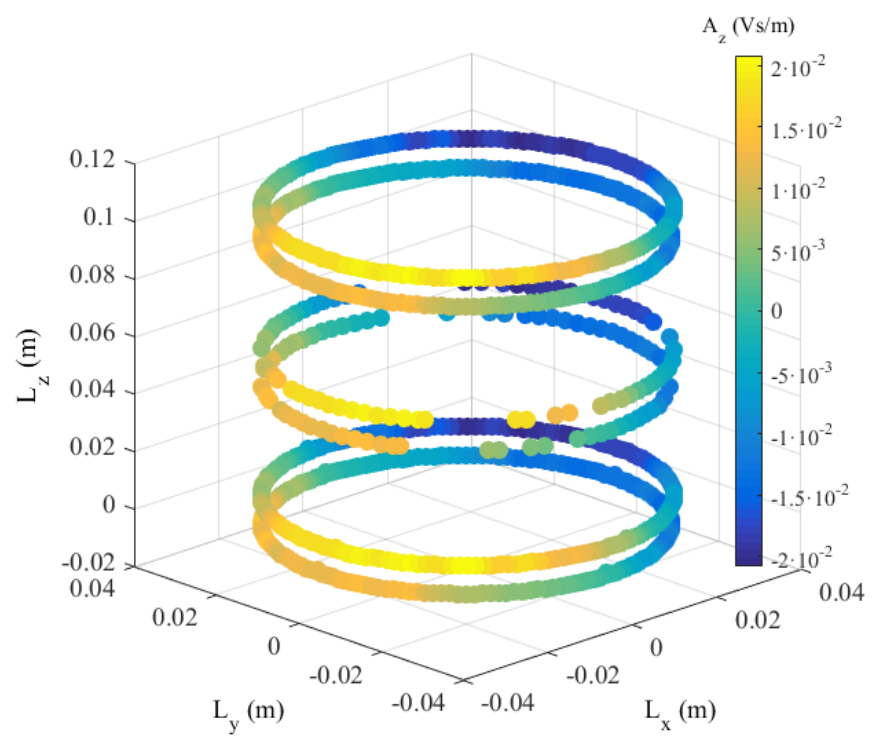

FIG. 3 Magnetic vector potential tangential component applied at the bottom, middle and top of the rotor iron nodes at $25 \mathrm{~ms}$ (lower) and $50 \mathrm{~ms}$ (upper). The values in the $z$ component have been displaced $\pm 0.01 \mathrm{~m}$ for visualization purposes.

\section{RESULtS}

\section{A. Electromagnetic results}

Fig. 4 shows a cutaway view of the rotor featuring the hot spot $45 \mathrm{~ms}$ after connection. The highest values of the flux magnetic density are observed next to the iron surfaces and especially on top of the bars, as it corresponds to a locked rotor condition. Furthermore, a magnetic coupling between the end ring and interbar currents and the shaft, just $5.25 \mathrm{~mm}$ apart in this small motor, is also appreciated. The integration of the magnetic energy in the shaft's end opposite to the hot spot yields an inductance value of $3.5 \cdot 10^{-11} \mathrm{H}$, three orders of magnitude below the value utilized in the $2 \mathrm{D}$ FE simulation for the end ring inductance.

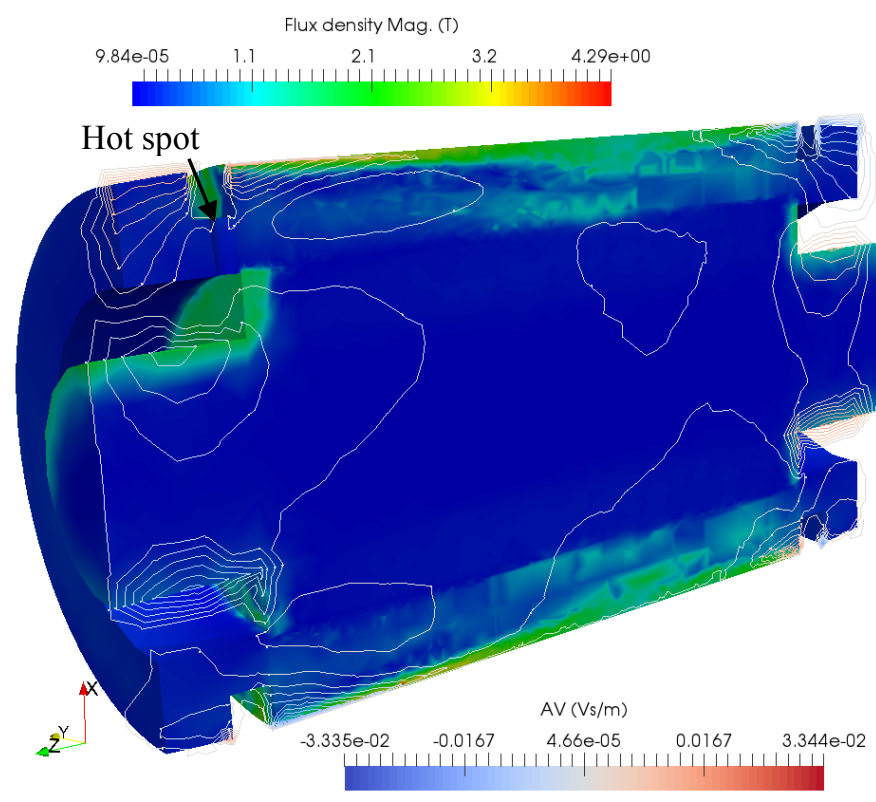

FIG. 4 Magnetic flux density and magnetic potential $45 \mathrm{~ms}$ after connection. The coupling between the end ring and the shaft is observed.

The current density in the cage and shaft, showing the skin effect, is presented in Fig. 5. The distribution is the expected one for the geometry of the conductors and the excitation frequency involved.

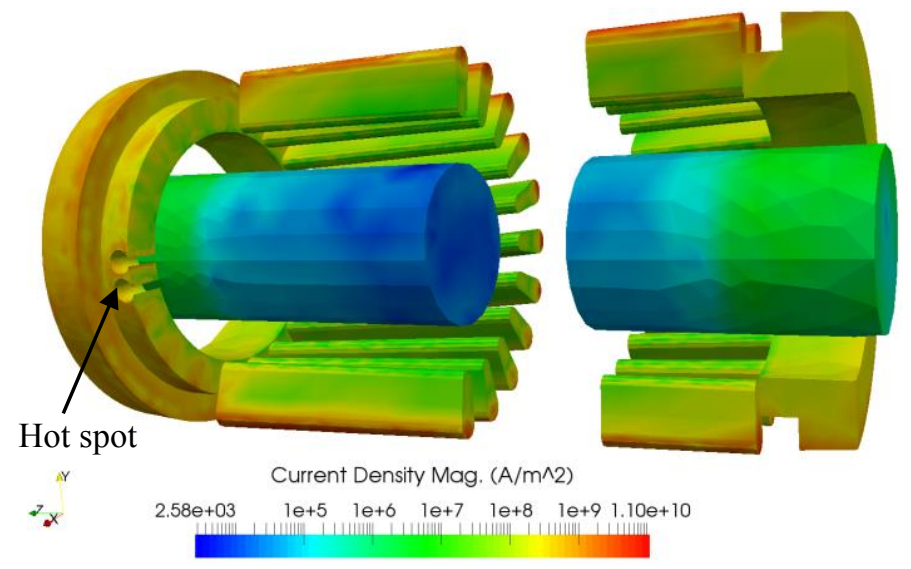

FIG. 5 Current density in the cage and shaft $45 \mathrm{~ms}$ after connection.

Finally, the current density in the radial direction at the middle of the hot spot is depicted in Fig. 6, showing a higher heating rate on the top and the bottom of the saddle compared to the average, at some time almost three times greater. The 
current in axial direction for the bar facing the saddle suffers a reduction of up to $3 \%$ (Fig. 7). It can also be appreciated some distortion on both ends of the diagram due to the reduction of the end rings' section. Since no aluminum is present at the top of the bars' ends, a sizeable amount of current crosses through the iron in these areas for this relatively high frequency and low iron resistance.

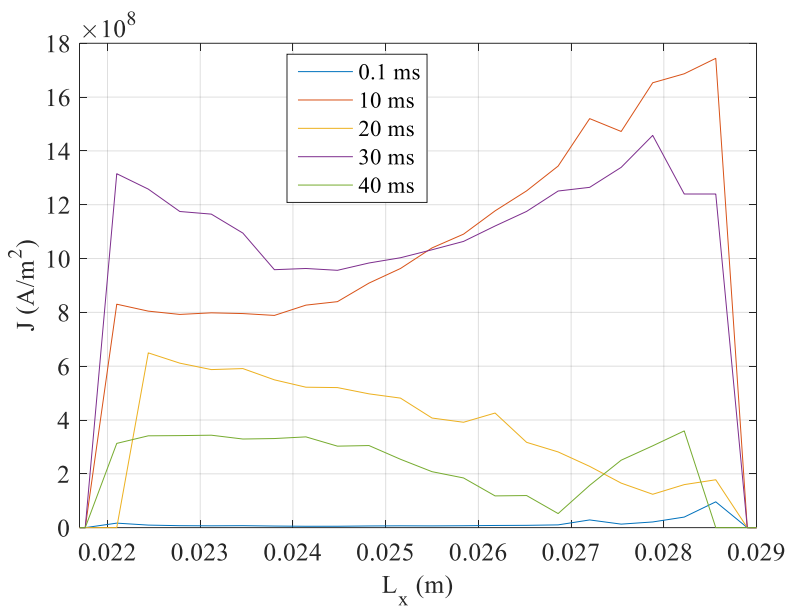

FIG. 6 Element current density across the hot spot in the radial direction $x$.

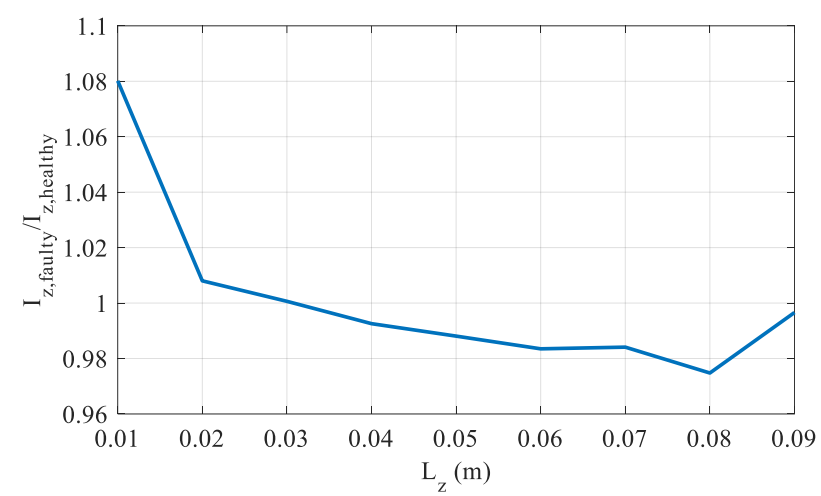

FIG. 7 Integrated current in the axial direction $z$ for the bar facing the hot spot, ratio between the hot spot and symmetrical state.

\section{B. Mechanical effects}

The results obtained from the weakly coupled linear elastic solver are presented in this section.

Electromagnetic induced stresses do not represent a sizeable mechanical load in the cage compared to thermal induced ones [5], as it is shown in Fig. 8, where the main body forces are observed in the iron yoke and shaft, especially in its supporting ends, with values up to $300 \mathrm{MPa}$. The end ring slightly increases it stress level for the hot spot case (Fig. 9), remaining the ones around the saddle area similar in both states. The overall maximum values are obtained in the ironaluminum interface, caused mainly by high tensile forces in the axial direction.

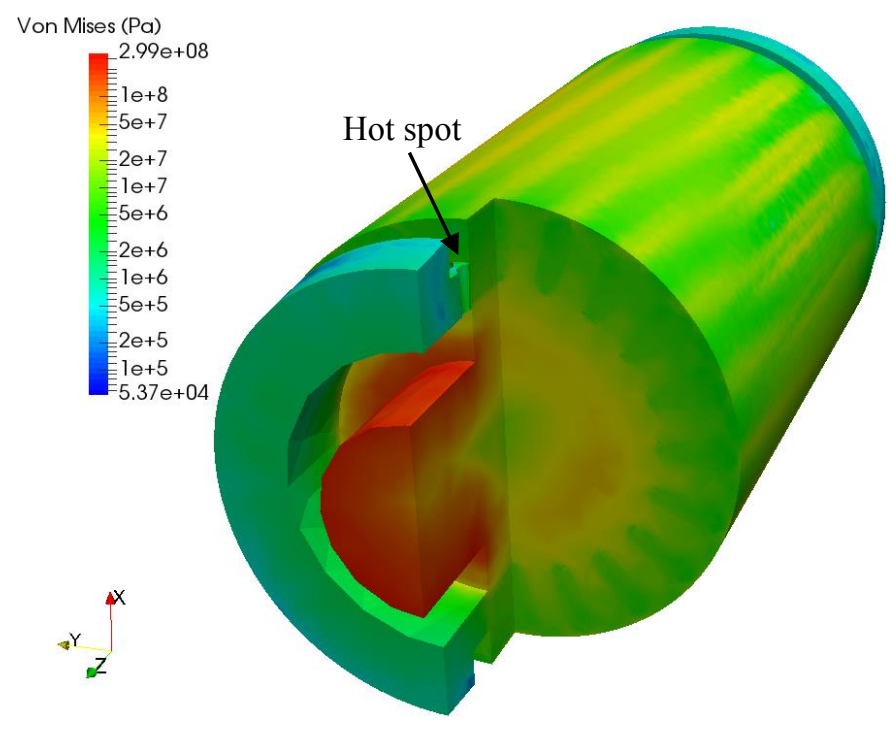

FIG. 8 Von Mises stress in the rotor $45 \mathrm{~ms}$ after connection.

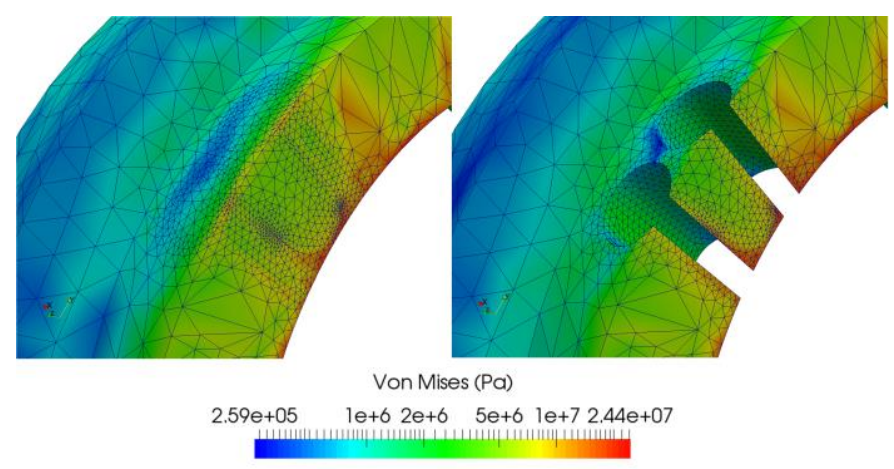

FIG. 9 Comparison of Von Mises stress in the symmetrical (left) and hot spot (right) cases $45 \mathrm{~ms}$ after connection.

Finally, Fig. 10 depicts the variation of the average axial stress ( $z$ direction) on the end surfaces of the shaft for both the symmetrical rotor (dashed line) and the one featuring the hot spot in one of its end rings (solid line). The curves between both states begin to slightly differ after $35 \mathrm{~ms}$ around some local extrema. An offset of $3.94 \cdot 10^{5} \mathrm{~Pa}$ for the hot spot's end and $1.14 \cdot 10^{5} \mathrm{~Pa}$ for the opposite is observed for both cases. Also a main component at the field frequency of $50 \mathrm{~Hz}$ is clearly detected, rapidly blurred by high frequency ones at around 500 and $1420 \mathrm{~Hz}$.

\section{CONCLUSIONS}

During the first instants after a direct-on-line connection the skin effect can cause substantial differential heating on imperfections in the rotor cage of an induction motor; however, electromagnetic-induced mechanical loads remain low. Under these conditions and for a small machine, a magnetic coupling between the end ring and interbar currents and the shaft is observed. The comparison of these results, obtained by means of a weakly coupled magneto-elastic 
model, with a healthy rotor simulation shows minor differences in the forces acting at both shaft ends

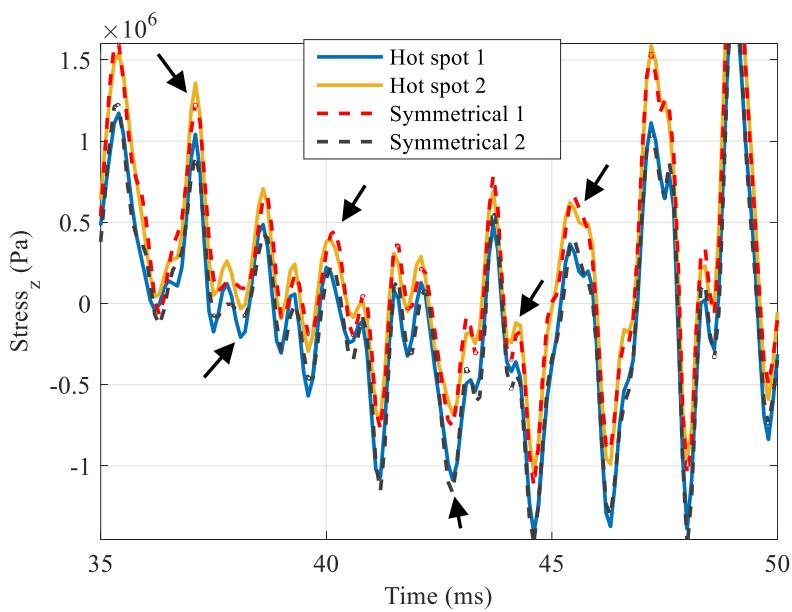

FIG. 10 Stress at both end sections of the rotor for the hot spot case (solid line) and symmetrical one (dashed line). The arrows point out some small differences around the local extrema.

\section{REFERENCES}

[1] M. Hodowanec, W. R. Finley, "Copper versus aluminum-which construction is best? [induction motor rotors]," IEEE Ind. Appl. Magazine, Vol. 8, 2002, pp. 14-25.

[2] J. Faiz; B. M. Ebrahimi, "A new pattern for detecting broken rotor bars in induction motors during start-up," IEEE Trans. Magn., vol. 44, no. 12, Dec. 2008

[3] M. F. Cabanas et Al., "Analysis of the fatigue causes on the rotor bars of squirrel cage asynchronous motors: Experimental analysis and modelling of medium voltage motors," in Proc. SDEMPED, 2003, pp. 247-252.

[4] C. D.Pitis, "Thermo-mechanical stresses of the squirrel cage rotors in adverse load conditions," in Proc. ISEI, 2008, pp. 579-585, Vancouver, $\mathrm{BC}$, Canada.

[5] V. Climente-Alarcon, D. Nair, R. Sundaria, J. A. Antonino-Daviu, A. Arkkio, "Combined Model for Simulating the Effect of a Heavy Transient on a Damaged Rotor Cage," Proc. of ICEM 2016, Lausanne, Switzerland, pp. 2867-2873.

[6] O. Biro, "Edge element formulations of eddy current problems," Comput. Methods in Appl. M., vol. 169, no. 3-4, 1999, pp. 391-405.

[7] Elmer Finite Element Software, CSC - IT Center for Science, FINLAND, [online], Available: https://www.csc.fi/web/elmer

[8] Keränen, J., et al. (2015), "Efficient parallel 3-D computation of electrical machines with Elmer", IEEE Trans. Magn., vol. 51, no. 3, pp. $1-4$.

[9] Yamazaki K. and Watanabe Y. (2005), "Stray load loss analysis of cage induction motors considering inter-bar currents using 3-D finite element method", IEEE International Conference on Electric Machines and Drives, 2005., San Antonio, TX, 2005, pp. 585-590.

[10] Yamazaki K. and Kanou Y., "Rotor Loss Analysis of Interior Permanent Magnet Motors Using Combination of 2-D and 3-D Finite Element Method", IEEE Trans. Magn., vol. 45, no. 3, 2009, pp. 1772-1775.

[11] Giet. D. V. M., Schlensok C., Schlmulling B. and Hameyer K., "Comparison of 2-D and 3-D Coupled Electromagnetic and StructureDynamic Simulation of Electrical Machines", IEEE Trans. Magn., vol. 44, no. 6, 2008, pp. 1594-1597.

[12] P. Handgruber, A. Stermecki, O. Biro, A. Belahcen and E. Dlala, "3-D eddy current analysis in steel laminations of electrical machines as a contribution for improved iron loss modeling," IEEE Trans. Ind. Appl., vol. 49, no. 5, 2013, pp. 2044-2052.
[13] A. Belahcen, "Magnetoelasticity, Magnetic Forces and Magnetostriction in Electrical Machines," Ph.D. dissertation, Dept. Elec. Comm. Eng., Aalto Univ., Espoo, Finland, 2004. 